San Jose State University

SJSU ScholarWorks

$1-1-1997$

\title{
The Differences Between Women and Men in the Length of Time Between Onset of Cardiac Symptoms and Undergoing a Cardiac Catheterization
}

Anita Gertsch

San Jose State University

Follow this and additional works at: https://scholarworks.sjsu.edu/etd_projects

Part of the Critical Care Nursing Commons

\section{Recommended Citation}

Gertsch, Anita, "The Differences Between Women and Men in the Length of Time Between Onset of Cardiac Symptoms and Undergoing a Cardiac Catheterization" (1997). Master's Projects. 853.

DOI: https://doi.org/10.31979/etd.9q7m-sa5h

https://scholarworks.sjsu.edu/etd_projects/853

This Master's Project is brought to you for free and open access by the Master's Theses and Graduate Research at SJSU ScholarWorks. It has been accepted for inclusion in Master's Projects by an authorized administrator of SJSU ScholarWorks. For more information, please contact scholarworks@sjsu.edu. 


\title{
THE DIFFERENCES BETWEEN WOMEN AND MEN IN THE LENGTH OF
}

TIME BETWEEN ONSET OF CARDIAC SYMPTOMS AND UNDERGOING A CARDIAC CATHETERIZATION

\author{
Anita Gertsch RN BSN CCRN \\ MS/FNP Student at San Jose State University School of Nursing \\ San Jose, Ca
}

Anita Gertsch






\begin{abstract}
Coronary artery disease is a leading cause of death among women. Even so, research suggests that women continue to receive less aggressive cardiac treatment than men. The purpose of the research was to determine if there was a time difference in initiation of cardiac catheterization in a selected population of men and women. A chart review was completed on adult women $(n=20)$ and men $(n=20)$, with varied adult ages, at a hospital based cardiac catheterization laboratory in Northern California. The charts were chosen randomly from the daily catheterization list. Data collection included age, gender, preferred spoken language, pay source, prior documented cardiac testing, history and physical, time and date when onset of signs and symptoms of cardiac disease began, and the time and date when cardiac catheterization was performed. The study failed to identify a difference between women and men in the length of time between onset of cardiac symptoms and undergoing a cardiac catheterization. However, the study did reveal a difference in presenting symptoms between men and women.
\end{abstract}




\section{Research Problem/Area of Inquiry}

Coronary artery disease $(\mathrm{CAD})$ is a leading cause of death in the United States of women over 40 years of age. ${ }^{1-6} \mathrm{CAD}$ consists of abnormal conditions that affect the coronary arteries' ability to provide adequate oxygen and nutrients to the myocardial tissue. When the coronary arteries are occluded or go into spasm, the blood flow to the myocardium is decreased which causes pain, angina pectoris. "Angina pectoris is defined as chest pain or discomfort of cardiac origin that usually results from a temporary imbalance between myocardial oxygen supply and myocardial oxygen demand. ${ }^{17}$ Failure to correct the occlusion will cause ischemia and eventually myocardial tissue infarction or death.

Women tend to live longer than men by 8 to 10 years, but "the outcome of women with coronary disease may be worse than that of their male counterparts." 1 "Death rates from coronary artery disease increase linearly until middle age in men and women, and begin to converge in late middle age such that men and women have similar incidence of coronary artery disease in older age groups."

Several factors appear to contribute to the increased incidence of $\mathrm{CAD}$ among women. First, it is well documented that being postmenopausal and lacking estrogen is associated with an increased risk of CAD. Second, as with their male counterparts, smoking, diabetes, hypertension, and hyperlipidemia also contribute to CAD in women. Third, the "baby boomer" population has begun to age which also 
increases the number of women with $\mathrm{CAD}$. Fourth, research has suggested that perhaps women's signs, symptoms, and treatments are managed less aggressively than men with $\mathrm{CAD} .{ }^{9,10}$

Women are at high risk for heart disease and other cardiac related problems, but have been studied less often than men. ${ }^{1,6,11}$ "The problem of cardiovascular disease in women has been largely ignored as women have been enrolled in limited numbers or excluded entirely from many of the major trials on which treatment of cardiovascular disease has been based."8

Purpose and Significance

"It is well established that women with myocardial infarction have a worse prognosis than men, but disagreement persists about whether this reflects differences in age, risk profiles, or treatment given."12 The purpose of this study was to determine if treatment is different for women as compared to men when cardiovascular function is compromised. Treatment is defined in the study as the length of time between onset of cardiac symptom or symptoms brought to the attention of their health care provider and the initiation of cardiac catheterization. Studies have shown that women with CAD undergo fewer major diagnostic and therapeutic procedures than men. ${ }^{9,13}$ Findings of this study have the potential to stimulate better education of women and health care providers, earlier intervention, treatment, and prevention of $\mathrm{CAD}$ among women. 
Research Question

This study explored the question: Is there a difference between women and men in the length of time between onset of cardiac symptoms and undergoing a cardiac catheterization? This question expanded into a series of questions, which are to (a) describe what men and women identify as pattern of symptoms, (b) identify demographic characteristics of selected geographic populations, (c) describe and compare cardiac symptoms of men and women, the types and numbers of cardiac diagnostic tests received, and (d) determine if there is a difference between men and women, emergent and non-emergent, in the time between onset of cardiac symptoms and undergoing a diagnostic cardiac catheterization. What factors may contribute to this difference? "The female heart is generally smaller and lighter and has smaller coronary vessels than does the male heart."6 This aspect alone contributed to why women did not receive cardiac catheterization in the past, but current development of smaller catheter lumens now prevent this problem. The goal was to determine if there is a time difference in initiation of cardiac catheterization in a selected population of men and women.

\section{Literature review}

A comprehensive literature review was completed based on research concerning women and cardiac disease, with special consideration given to age, gender, risk factors, and other factors which may contribute to a delay in receiving 
care. "Because of the later onset of clinical coronary heart disease in women . . . the older age of female patients compared with male patients is a major explanation of the poorer survival of women. "With regard to the higher mortality of women, it seems that although it is less frequent, ischemic heart disease is more severe in women than in men."10

Diagnosis of $\mathrm{CAD}$ should include information from a thorough history, physical exam, and ancillary tests such as chest x-ray and electrocardiogram; however, these exams may not be conclusive in women. It is unclear what the optimal method is to evaluate $\mathrm{CAD}$ in women. "Typical" anginal pain [sternal pain radiating to the left arm] predicted $\mathrm{CAD}$ in $93 \%$ of men but in only $72 \%$ of women. ${ }^{15}$ During stress testing, it "has been known for decades that women are more likely than men to have electrocardiography (ECG) abnormalities with exercise despite a lower prevalence of coronary disease in women compared with men. . . suggesting [stress testing to be] a less useful diagnostic test in women than in men." Echocardiography has been useful in the diagnosis of CAD in men. It has been found that using dipyridamole with stress testing was superior to ECG stress testing in women. ${ }^{16}$ According to Wackers, imaging modality sensitivity should be increased with thallium, but may be limited by technical problems in women. ${ }^{17}$ False positive thallium imaging may result in women because of "attenuation of radioactivity by overlying breast tissue. ${ }^{13}$ Overall gender differences exist when 
utilizing noninvasive diagnostic tests for diagnosis of $\mathrm{CAD}$. Determination of $\mathrm{CAD}$ in women can be inconclusive with noninvasive procedures and this may further delay appropriate treatment. More assertive or aggressive measures could be utilized earlier for correct diagnosis of CAD.

The "gold standard" for the presence of coronary disease remains coronary arteriography. . . performed in the cardiac catheterization laboratory. ${ }^{1}$ This procedure uses a radiopaque material which is injected into the coronary arteries and allows cineangiographic visualization of coronary arterial narrowing or occlusion. "Several investigators have suggested that the greater mortality associated with coronary artery disease in women may be related to a bias against referring women for coronary arteriography."8 Ayanian and Epstein concluded that hospitalized women with $\mathrm{CAD}$ undergo fewer major diagnostic and therapeutic procedures than men, suggesting that bias plays a part in whether women receive beneficial procedures. $^{9}$

Women may be referred for coronary surgery at a more advanced stage of disease than men. The question may be asked: Why are women so much more advanced in cardiac disease than men when they are referred for surgery? "Women were older than men by a average of 8 years . . and presented nearly 1 hour later in the course of their infarct."18 Possible reasons for treatment delays include: (a) medical bias, because women are looked at and treated differently than men, (b) 
cultural factors, because women's values and beliefs differ, directly affecting their willingness to seek help and accept treatment, (c) societal expectations, because we expect men to have myocardial infarctions and not women, and (d) financial difficulties, because more women live below the poverty level than men and poverty seriously limits access to adequate health care.

\section{Conceptual Framework}

The conceptual framework underlying this study is Feminist Theory. Feminist approaches are manifested when a discipline is concerned with women's issues and experiences. ${ }^{19}$ The 'today's' women is increasing control over her health care. More women are accessing information to increase their knowledge about health care needs and beginning to make informed decisions about medical treatment. But women continue to fall behind men when it comes to health care, and therefore, continue to struggle for women's health. "Women's health is about much more than particular reproductive organs and secondary sex characteristics. Women's health is constructed in ways that are often different from those of men and therefore the health issues women face are often different from those of men."20 As stated by Andersen "there are eighty-one chances out of one hundred that the person [medical professional] she sees will be a man."21

\section{Methodology}

The study was conducted at a hospital based cardiac catheterization laboratory 
in Northern California. A convenience sample from medical records for men $(n=20)$ and women $(n=20)$ with diverse ethnic and religious backgrounds were drawn from the daily catheterization list taken during a one month period. The criteria for inclusion in the study was a subject presenting with cardiac symptoms and having their first time cardiac catheterization. If the subject did not meet the criteria, then the next chart was reviewed until the desired quota was reached. A chart review was completed on each subject. This review gathered information on age, gender, preferred spoken language, pay source, prior documented cardiac testing, and the cases were divided into emergent and non-emergent. The pay source was divided into the following six categories: Health Maintenance Organization (HMO), Preferred Provider Organization (PPO), Medi-Care, Medi-Cal, private and self-pay. The history and physical were reviewed to identify the pattern of symptoms and to determine the reported date and time the symptoms began and the reported date and time the cardiac catheterization was performed.

\section{Data Analysis}

Demographic variables were collected from the chart review. The data consisting of age, gender, preferred spoken language, pay source, prior documented cardiac testing were analyzed using descriptive statistics. The difference between men and women in the length of time between onset of cardiac symptoms and undergoing a cardiac catheterization were compared using a two tail t-test, pooled 
and non-pooled.

\section{Results}

\section{Demographic Data}

Seventy-five percent of the male subjects and eighty percent of the female subjects spoke English. Fifteen percent of males and females spoke Spanish. Both male and female had 5\% Filipino speaking subjects. Five percent of the males spoke Hindi.

The range of ages for the men was 44 to 84 years with a mean of 62 $(\mathrm{SD}=13.47)$, and the range of women was 48 to 86 years with a mean of 69 $(\mathrm{SD}=11.88)$. There were no statistical differences between the ages of men and women receiving a cardiac catheterization.

The pay sources showed no differences between men and women. Forty percent of men and fifty percent of women used Medi-care as their primary coverage. There were three males and four females using Medi-cal as their primary coverage. The other subjects in both categories were enrolled in an HMO alone or in conjunction with a spouses PPO.

Symptomatology Data

Table 2 outlines the similarities and differences of cardiac symptomatology between males and females. The male subjects described their cardiac symptoms as pressure across the front of the chest, epigastric burning pain, a dull pain, substernal 
pain with heavy sensation, squeezing chest pain, left arm and jaw pain, nausea, diaphoresis, shortness of breath, or described having a sense of fear. The men described these symptoms during emergent and non-emergent situations. However, women differed in their cardiac symptoms. Their description included a bandlike sensation in the midsternum, a burning pain, left arm and jaw pain, a squeezing and choking sensation, intermittent chest pain with tightness and palpitations, shortness of breath, nausea or diaphoresis. These symptoms were present only during emergent situations, During non-emergent visits women described their symptoms as shortness of breath on exertion, epigastric pain, pain in the back of the chest, orthopnea, or intermittent chest discomfort and fullness when walking up a hill. These symptoms are quite different from their males counterparts for non-emergent chest discomfort.

Diagnostic Testing Data

The diagnostic tests among men and women included electrocardiogram (ECG), chest X-ray (CXR), echocardiogram (Echo), and stress testing. Stress testing is defined as a procedure in which the subjects cardiac response to increasing physical stress was monitored for myocardial ischemia, abnormal blood pressure, and arrhythmias. Table 3 outlines these data. When the data were analyzed in percentages, no difference between men and women were noted among CXR and ECG. Men received 15\% more echocardiograms and 35\% more stress testing than 
women. Among the emergent cases $100 \%$ of the men $(n=10)$ and $100 \%$ of the women $(n=4)$ had both an ECG and a CXR performed and echocardiograms were performed on 9 men (90\%) and 3 women (75\%). Among the non-emergent cases $100 \%$ of the men $(n=10)$ and $100 \%$ of the women $(n=16)$ received an EKG and CXR. Sixty percent of the men underwent stress testing prior to a catheterization but only twenty-five percent of the women. This discrepancy in cardiac stress testing suggests that women undergo fewer noninvasive procedures than men for non-emergent situations. It is unknown how long these subjects had complained of some type of cardiac symptoms to their primary healthcare provider before receiving a diagnostic stress test.

\section{Statistical Analysis}

The time, measured in days, between onset of heart symptoms and diagnostic cardiac catheterization was compared by using a pooled and non-pooled 2 tail t-test. Table 4 outlines the analyzed data. The men had a mean of 10.508 days and SD of 21.070. The females mean were 23.752 days and a SD of 33.815 . Using an significance level of $\alpha 0.05$, the data failed to identify a difference between men and women in the onset of cardiac symptoms and undergoing a cardiac catheterization. The data were then edited and the emergent cases of both men and women were removed. Table 5 outlines the analyzed data. The mean for the men was 18.4 days and the mean for the women were 29.5 days. When the data were non-pooled the 
variances were non-equal. The SD for men were 27.512 and women were 35.667 . Again the data failed to identify a significant difference in treatment between men and women for all cases and for non-emergent cases.

\section{Limitations of the Study}

There are several limitations in the study. The information was taken from hospital charts and represented the interpretation of the attending physician performing the cardiac catheterization. This investigator wonders if the study may have had a different outcome if an interview was done with each of the subjects to identify exactly when their cardiac symptoms began, verifying the history. The results were based on a small sample size. Larger studies may reveal statistically significant results.

It should also be taken into consideration that the sample was derived from a single institution. The hospital in which the study was performed, has advanced quickly in its ability to perform cardiac catheterizations for the residents of Monterey County. It provides up to date equipment and a very medically aggressive medical staff, which decreases the amount of time it takes to undergo a cardiac catheterization. The cardiac catheterization procedure is not available in all hospitals. Therefore, other facilities may need to refer the patient to another location where the service is available, which may be in another town. Further studies using other samples and clinical settings need to be performed. 
Conclusion

This study demonstrates that women and men are similar when compared in time between onset of cardiac symptoms and that of undergoing a cardiac catheterization. The apparent difference between the two groups were that women received stress testing less often than men, were seen less often in emergent situations than men, and identified different cardiac symptomatology than men.

Women's symptoms of CAD may not be typical compared to men, especially in the early stages of the disease. The study findings demonstrate very different cardiac symptoms between women and men. The significance of these symptoms among women is quite often unappreciated by health care providers. More rapid attention must be provided to women complaining of these atypical cardiac symptoms in order to prevent treatment delay in the future. Family Nurse Practitioners (FNP) provide care to patients throughout the lifespan, and women's health is an important portion of the FNP's practice. Assessment of cardiovascular risk among women should be an integral part of women's health care. "Because $\mathrm{CAD}$ is now described as an equal opportunity killer, women must be taught strategies to overcome barriers to risk factor reduction."3 As stated before, women do not always present with the classic symptoms of CAD and therefore may be misdiagnosed. It is imperative that practitioner's realize these differences and develop new approaches to ensure high-quality care. Implementation of medical 
therapy should be based on a through history and physical and the complaint of chest pain or discomfort should be taken seriously and investigated in all women patients. Validation of cardiac symptoms should be determined by providing adequate testing, noninvasive and invasive.

This study also discovered that men are seen emergently more often than women with a cardiac event, suggesting that women do not have $\mathrm{CAD}$ as often as men, tolerate their symptoms longer, or are misdiagnosed. Women develop symptoms about 10 years later than men ${ }^{22}$ yet almost half of all MI deaths are among women. ${ }^{23}$ Therefore, $\mathrm{CAD}$ is a problem among women and should be identified early in its course. Women who develop a variety of aches, pains, and other physical manifestations may tolerate these as a normal part of human existence ${ }^{24}$ If severe or intense pain goes away quickly, a women may compensate and then dismiss those signs and symptoms completely. Atypical cardiac symptoms among women do not fit the stereotypical picture of a man clenching his fist over his chest during a cardiac event. ${ }^{11}$ Atypical signs and symptoms, including epigastric pain and shortness of breath, may delay diagnosis of $\mathrm{CAD}$ by health care providers. Women need to be educated by health care providers to recognize early the signs and symptoms of $\mathrm{CAD}$ and to seek medical attention, thereby preventing serious outcomes.

Cardiac disease is an important health issue for women and should be 
considered when doing research. "Research and funding have previously been conducted and controlled primarily by men using male subjects and male life experiences. There has been little emphasis on the needs and differences of female subjects and their life experiences." "Y "Yet the results of studies with men are used daily to make diagnostic and intervention decisions related to women." ${ }^{3}$ Therefore, women should be encouraged to participate in more studies.

Further research is necessary to identify if cardiac catheterization is indeed delayed among women. Once these data are obtained, nursing and medical professionals can provide patient teaching and prompt adequate care for women with cardiovascular disease. Anticipating needs will insure having the resources available. Further nursing research must be completed in the area of women with cardiac disease to enhance treatment. Accurate data are necessary for the future of women's health. The National Institutes of Health have recognized the need for women in research and have formed an interdisciplinary Women's Health Research Center. This center is dedicated to women's health and the development of women's research. 
Table 1

Ages of subjects

\begin{tabular}{|c|c|c|c|}
\hline Gender & Y & Milear & SD \\
\hline Men & $44-84$ & 62 & 13.47 \\
\hline Women & $48-86$ & 69 & 11.88 \\
\hline
\end{tabular}


Table 2

Comparison of cardiac symptomatology

\begin{tabular}{|c|c|c|}
\hline Emergent / Non-emergent & $\begin{array}{l}\text { Women } \\
\text { Emergent }\end{array}$ & $\begin{array}{l}\text { Women } \\
\text { Non-mergent }\end{array}$ \\
\hline $\begin{array}{l}\text { Pressure across front of } \\
\text { chest }\end{array}$ & $\begin{array}{l}\text { Bandlike sensation in } \\
\text { midsternum }\end{array}$ & $\begin{array}{l}\text { Shortness of breath on } \\
\text { exertion }\end{array}$ \\
\hline Epigastric burning pain & Burning chest pain & Epigastric pain \\
\hline Dull chest pain & Palpation's & Orthopnea \\
\hline $\begin{array}{l}\text { Substernal with heavy } \\
\text { sensation }\end{array}$ & $\begin{array}{l}\text { Squeezing and choking } \\
\text { sensation }\end{array}$ & Pain in the back of the chest \\
\hline Squeezing chest pain & $\begin{array}{l}\text { Intermittent chest pain with } \\
\text { tightness }\end{array}$ & $\begin{array}{l}\text { Intermittent chest } \\
\text { discomfort and fullness } \\
\text { when walking up a hill }\end{array}$ \\
\hline Left arm pain & Left arm pain & \\
\hline Jaw pain & Jaw pain & \\
\hline Nausea & Nausea & \\
\hline Diaphoresis & Diaphoresis & \\
\hline Shortness of breath & Shortness of breath & \\
\hline Sense of fear & & \\
\hline
\end{tabular}


Table 3

Percentage (\%) of Diagnostic Testing

EMERGENT CASES

\begin{tabular}{|c|c|c|}
\hline Diagnostic Test & Men $(n=10)$ & Women $(n=4)$ \\
\hline EKG & $100 \%$ & $100 \%$ \\
\hline CXR & $100 \%$ & $100 \%$ \\
\hline ECHO & $90 \%$ & $75 \%$ \\
\hline
\end{tabular}

NON-EMERGENT CASES

\begin{tabular}{|c|c|c|}
\hline Diagnostic rest & Mern (n-10) & Women $(n-16)$ \\
\hline EKG & $100 \%$ & $100 \%$ \\
\hline CXR & $100 \%$ & $100 \%$ \\
\hline Stress Testing & $60 \%$ & $25 \%$ \\
\hline
\end{tabular}


Table 4

Time between onset of symptoms and undergoing cardiac catheterization

[Months]

\begin{tabular}{|c|c|c|c|c|}
\hline Gender & Mean & SD. & $\begin{array}{l}\text { Pooled } \\
\text { p-valiae }\end{array}$ & Won poroved \\
\hline $\begin{array}{c}\text { Men }(n=20) \\
\text { Women }(n=20)\end{array}$ & $\begin{array}{l}0.350 \\
0.791\end{array}$ & $\begin{array}{l}0.702 \\
1.127\end{array}$ & 0.145 & 0.147 \\
\hline
\end{tabular}

[Days]

\begin{tabular}{|c|c|c|c|c|}
\hline Gender & Mean & SD & $\begin{array}{l}\text { pooled } \\
\text { p-value }\end{array}$ & $\begin{array}{l}\text { Non pooled } \\
\text { povalue }\end{array}$ \\
\hline $\begin{array}{c}\text { Men }(n=20) \\
\text { Women }(n=20)\end{array}$ & $\begin{array}{l}10.508 \\
23.752\end{array}$ & $\begin{array}{l}21.070 \\
33.815\end{array}$ & 0.145 & 0.147 \\
\hline
\end{tabular}

No significance@p-value $>0.05$ 
Table 5

Edited time between onset of symptoms and undergoing cardiac catheterization

\section{[Days]}

Pooled with equal variances

\begin{tabular}{|c|c|c|}
\hline Gender & Mean & P value \\
\hline Men $(\mathrm{n}=10)$ & 18.4 & 0.401 \\
& 29.5 & \\
\hline
\end{tabular}

Non-pooled with non-equal variances

\begin{tabular}{|c|c|c|}
\hline Gender & SB & P value \\
\hline Men $(\mathrm{n}=10)$ & 27.512 & 0.38 \\
& 35.667 & \\
Women $(\mathrm{n}=4)$ & & \\
\hline
\end{tabular}

No significance @ p-value $>0.05$ 


\section{References}

1. Cole PL: Coronary artery disease in women. Curr Science 1993; 4:595-604.

2. Creel C: Silent myocardial ischemia and nursing implications. Heart \& Lung $1994 ; 23: 218-226$.

3. Murdaugh C: Coronary artery disease in women. J Cardiovasc Nurs $1990 ; 4(4): 35-50$.

4. King KM, Gortner SR: Women's short-term recovery from cardiac surgery. Prog Cardio Nurs 1996;153:2626-2636.

5. Wenger NK: Coronary heart disease in women: A 'new' problem. Hosp Prac 1992;Nov 15:59-74.

6. Wingate S: Women and coronary heart disease implications for the critical care setting. Focus Crit Care 1991;18:212-220.

7. O'Rourke RA: Chest pain. In: Schlant RB, Alexander RW, eds. The heart arteries and veins. New York: McGraw-Hill, 1994;459-559.

8. Kuhn FE, Rackley CE: Coronary artery disease in women. Arch Intern Med $1993 ; 153: 2626-2636$.

9. Ayanian JZ, Epstein AM: Differences in the use of procedures between women and men hospitalized for coronary heart disease. N Engl J Med 1991;325:221225. 
10. Kahn SS, Nessim S, Gray R, Czer LS, Chaux A, Matloff J: Increased mortality of women in coronary artery bypass surgery: Evidence for referral bias. Ann Inter Med 1990;112:561-567.

11. Douglas PS: Gender, cardiology, and optimal medical care. Circulation 1986;74:917-919.

12. Wilkinson $\mathrm{P}$, Laji K, Ranjadayalan K, Parsons L, Timmis AD: Acute myocardial infarction in women: survival analysis in first six month. BMJ 1994;309:566569.

13. D'Hoore D, Sicotte C, Tilquin C: Sex bias in the management of coronary artery disease in Quebec. AM J Public Health 1994;84:1013-1015.

14. Vaccarino V, Krumholz HM, Berkman LF, Horwitz RI: Sex differences in mortality after myocardial infarction: Is there evidence for an increased risk for women? Circulation 1995;91:1861-1871.

15. Chaitmna BR, Bourassa MG, Davis K, Rogers WJ, Tyres DH, Berger R: Angiographic prevalence of high-risk coronary artery disease in patient subsets (CASS). Circulation 1981;64:360-367.

16. Sawada SG, Ryan T, Fineberg NS, Armstrong WF, Judson WE, McHenry PL, Feigenbaum $\mathrm{H}$ : Exercise echocardiographic detection of coronary artery disease in women. J Am Coll Cardiol 1989;14:1440-1447. 
17. Wackers FJ: Diagnostic pitfalls of myocardial perfusion imaging in women. $J$ Myocardial Img 1992;4:23-48.

18. Stone GW, Grines CL, Browne KF, Marco J, Rothbaum D, O’Keefe J, Hartzler GO, Overlie P, Donohue B, Chellish N, Vlietstra R, Puchrowicz-Ochocki S, O'Neill WW: Comparsion of in-hospital outcome in men versus women treated by either thrombolytic therapy or primary coronary angioplasty for acute myocardial infarction. Am J Cardiol 1995;75:987-992.

19. Meleis AI: Revisions in knowledge development: A passion for substance. In: Nicoll LH, ed. Perspectives on nursing theory. New York: JB Lippincott, 1992:118-126.

20. Armstrong P: Women and health: Challenges and changes. In: Mandall N, ed. Feminist issues: Race, class and sexuality. Scarborough: Prentice-Hall, 1995:294-314.

21. Andersen ML: Thinking about women: Sociological perspectives on sex and gender. New York: Macmillan, 1993:208.

22. Mcbride AB: Developing a women's mental health research agenda. Image 1987;19:4-8.

23. Lerner DJ, Kannel WB: Patterns of coronary heart disease morbidity and mortality in the sexes: A 26 year follow-up of the Framingham population. AM Heart J 1986;111:383. 
24. Scherck KA: Recognizing a heart attack: The process of determining illness. AM J Crit Care 1997;6(4):267-273. 